\title{
Oncocytic carcinoma of parotid gland: a case report with clinical, immunohistochemical and ultrastructural features Giovanna Giordano*1, Marzio Gabrielli ${ }^{1}$, Letizia Gnetti ${ }^{1}$ and Teore Ferri ${ }^{2}$
}

\author{
Address: ${ }^{1}$ Department of Pathology and Medicine Laboratory, Section of Pathology, Parma University, Italy and ${ }^{2}$ Department of Otolaryngology, \\ Parma University, Italy \\ Email: Giovanna Giordano* - giovanna.giordano@unipr.it; Marzio Gabrielli - gabrielli@ao.pr.it; Letizia Gnetti - letizia117@virgilio.it; \\ Teore Ferri - teore.ferri@unipr.it \\ * Corresponding author
}

Published: 21 August 2006

World Journal of Surgical Oncology 2006, 4:54 doi:10.1 186/1477-7819-4-54

This article is available from: http://www.wjso.com/content/4/I/54

(c) 2006 Giordano et al; licensee BioMed Central Ltd.

This is an Open Access article distributed under the terms of the Creative Commons Attribution License (http://creativecommons.org/licenses/by/2.0), which permits unrestricted use, distribution, and reproduction in any medium, provided the original work is properly cited.
Received: 13 March 2006

Accepted: 2I August 2006

\begin{abstract}
Background: Oncocytic carcinoma is an extremely rare neoplasm of the salivary glands. We report a case of oncocytic carcinoma arising in a parotid gland in a 66-year-old female.

Method: An excisional biopsy of the parotid tumor was performed. The specimen was submitted for histology and after fixation in formalin solution and inclusion in paraffin, 3-5 $\mu \mathrm{m}$ sections were stained with hematoxylin and eosin for conventional evaluation and Periodic acid Schiff stain. Immunohistochemical studies were performed using antibodies against mitochondrial antigen, keratin, S-100, alpha-actin, vimentin, alpha-I-antichymotrypsin as well as an ultrastructural analysis was performed.

Results: Frozen sections revealed an infiltrative growth pattern and the diagnosis of a malignant epithelial lesion was made. Permanent sections stained with haematoxylin and eosin revealed a neoplasm that had replaced a wide area of the parotid gland and had invaded subcutaneous adipose tissue. Perineural invasion was evident, but vascular invasion was not found. Neoplastic elements were large, round or polyhedral cells and were arranged in solid sheets, islands and cords. The cytoplasm was abundant, eosinophilic and finely granular. The nuclei were large and located centrally or peripherally. The nucleoli were distinct and large. Periodic acid Schiff stain demonstrated a granular cytoplasm. Immunohistochemistry demonstrated mithochondrial antigen, keratin, and chymotrypsin immunoreactivity in the neoplastic cells. Ultrastructural analysis revealed numerous mitochondria packed into the cytoplasm of the neoplastic cells. Thus, the final diagnosis was that of oncocytic carcinoma of parotid gland.
\end{abstract}

Conclusion: This neoplasm shows clinical, microscopical, histological and ultrastructural features of oncocytic carcinoma and this must be considered in the differential diagnosis of other proliferations in the parotid gland with abundant granular cytoplasm and metastatic oncocytic carcinomas.

\section{Background}

The occurrence of oncocytic carcinoma of the parotid gland is rare. A new case of oncocytic carcinoma in a parotid gland has been reported recently by Guclu et al [1]. According to a review of the literature performed by these authors, only 41 cases have been reported [1]. We 
Table I: Primary antibodies used for immunophenotyping

\begin{tabular}{cccc}
\hline Antibody & Manufacturer & Dilution & Method \\
\hline Mitochondrial antigen & BioGenex & $1: 500$ & $\mathrm{ABC}$ \\
Citok $\mathrm{AE}_{1} / \mathrm{AE}_{3}$ & Dako & $\mathrm{I}: 100$ & $\mathrm{ABC}$ \\
CEA & Dako & $1: 25$ & $\mathrm{ABC}$ \\
Vimentin & Neomarkers & $1: 500$ & $\mathrm{ABC}$ \\
Alpha-I-anticymotrypsin & Dako & $1: 800$ & $\mathrm{ABC}$ \\
Smooth muscle actin & Neomarkers & $1: 500$ & $\mathrm{ABC}$ \\
SI00 protein & BioGenex & $1: 500$ & $\mathrm{ABC}$ \\
\hline
\end{tabular}

report a case of oncocytic carcinoma of the parotid gland with its clinical manifestations and pathological features.

\section{Case presentation}

A 66-year-old female was admitted to our Institution with a history of a painless left preauricular nodule that had gradually increased in size. Computed tomographic (CT) scan revealed a $2 \times 2.5 \mathrm{~cm}$ solid lesion in the left parotid gland. Cervical and peri-aortic lymph nodes were not enlarged, except for one in the submandibular region.

Total parotidectomy with preservation of the facial nerve was performed. Thus, the parotid gland and covering skin
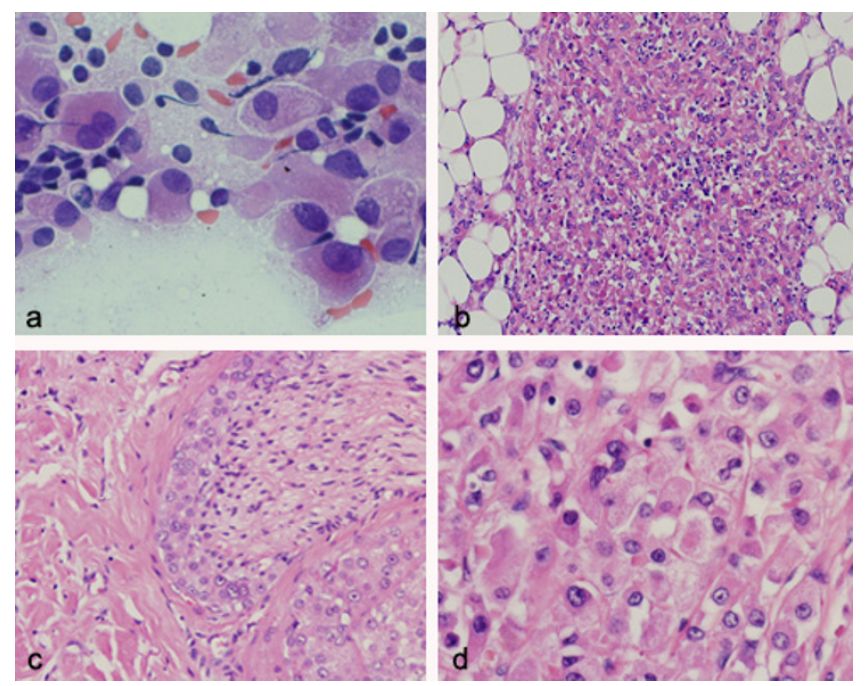

\section{Figure I}

Imprint cytology of lesion showing cohesive clusters of neoplastic cells with abundant and finely granular cytoplasm and moderately pleomorphic nuclei located centrally or peripherally (a: haematoxylin- eosin, $\times 400$ ). Permanent sections revealed a neoplasm that had invaded subcutaneous adipose tissue (b: haematoxylin- eosin, $\times 100$ ) and perineural tissue (c: haematoxylin-eosin, $\times 200$ ). Neoplastic elements with abundant granular eosinophilic cytoplasm, large nuclei and evident nucleoli, are large, round or polyhedral cells arranged in solid sheets, islands and cords (d: haematoxylin-eosin, $x$ 400). were removed. Lateral jugular lymph nodes dissection was carried out.

The lesion was initially examined in frozen sections. The specimen was submitted for histology and after fixation in formalin solution and inclusion in paraffin, 3-5 $\mu \mathrm{m}$ sections were stained with haematoxylin and eosin for conventional evaluation and a Periodic acid Schiff stain also carried out. A panel of immunostains, including antibodies against mitochondrial antigen, keratin (Citok AE1, Citok AE3), carcinoembryonal antigen (CEA), vimentin, alpha-1-antichymotrypsin, smooth muscle actin and S100, was applied to representative sections of the tumour using the avidin-biotin complex technique (Table 1). Formalin-fixed small fragments of neoplasm were also examined by electron microscopy, after washing in $0,1 \mathrm{M}$ phosphate buffer, postfixation in osmium tetroxide, dehydratation in ethanol and embedding in epon-araldite.

Ultrathin sections were stained with uranyl acetate and lead citrate and examined with a Philips EM 208 electronic microscope.

\section{Results}

Macroscopically, the tumour was a well-circumscribed, firm, grey-brown, ovoid nodule measuring $2.5 \mathrm{~cm}$ in diameter. Imprint cytology of the lesion showed cohesive clusters of neoplastic cells. The cytoplasm was abundant and finely granular. The nuclei were moderately pleomorphic, medium or large and were located centrally or peripherally (Figure 1a). Frozen section revealed an infiltrative growth pattern and the diagnosis of a malignant epithelial lesion was made.

Permanent sections stained with haematoxylin and eosin revealed that the neoplasm that had replaced a wide area of the parotid gland and had invaded subcutaneous adipose tissue (figure $1 \mathrm{~b}$ ). Perineural invasion was evident (figure 1c), but vascular invasion was not found. Neoplastic elements were large, round or polyhedral cells and were arranged in solid sheets, islands and cords. The cytoplasm was abundant, eosinophilic and finely granular. The nuclei were large and located centrally or peripherally. The nucleoli were distinct and large (figure 1d). Periodic acid Schiff stain demonstrated a granular cytoplasm.

Immunohistochemically, the tumour strongly reacted with mithochondrial antigen (Figure 2a), keratin (Figure 2b), alpha-1-antichymotrypsin (Figure $2 \mathrm{c}$ and $2 \mathrm{~d}$ ), but was negative for smooth muscle actin, vimentin and carcinoembryonal antigen (CEA) and S-100 protein (S-100). All lymph nodes examined were negative for metastases. 

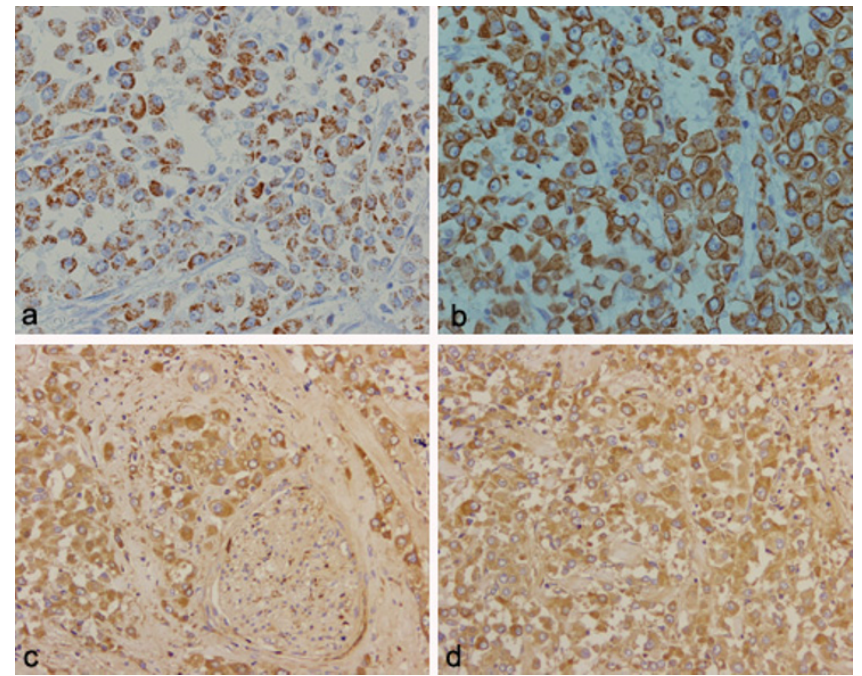

\section{Figure 2}

All tumour cells on immunohistochemical study showed finely granular immunoreactivity of the cytoplasm with antimitochondrial antibody (a: $\times 200)$, cytoplasmatic and membranous positivity for antikeratin antibody $(b: \times 200)$ and cytoplasmatic positivity for alpha-I-antichymotripsina (c and $\mathrm{d}$ : $\times 200$; in c yet note neoplastic perineural infiltration).

On ultrastructural examination, the cytoplasm of neoplastic cells seemed to be packed with numerous mitochondria. These organuli were not clear, since their cristae appeared fragmented because of fixation in formalin solution without adjusted $\mathrm{pH}$.

\section{Discussion}

Oncocytic carcinoma is an extremely rare malignancy in salivary glands, accounting only for $11 \%$ of all oncocytic salivary gland neoplasms, $0.5 \%$ of all epithelial salivary gland malignancies and $0.18 \%$ of all epithelial salivary gland tumours [2]. This neoplasm is characterized by epithelial cells with abundant eosinophilic and granular cytoplasm, filled with numerous mitochondria.

Malignant oncocytoma, malignant oxyphilic adenoma and oncocytic adenocarcinoma have been used synonymously for oncocytic carcinoma. The malignant nature of the neoplasm can be recognized by its morphologic features and infiltrative growth. Morphologic criteria for the diagnosis of a malignant nature are cellular pleomorphism, necrosis and frequent mitoses. Infiltrative growth of the neoplasm is represented by perineural, vascular or lymphatic invasion, destruction of adjacent structures and local lymph node metastasis.

Immunohistochemical study and ultrastructural examination are essential ancillary studies necessary for a correct diagnosis of oncocytic carcinoma to be made; these proce- dures show the presence of abundant mitochondria in cytoplasm.

In our case, the malignant nature of the neoplasm was evidenced by the presence of perineural invasion and by infiltration of subcutaneous tissue. No regional or distant lymph node metastases clinically or radiologically were observed.

Oncocytic differentiation of neoplastic cells was demonstrated by immunohistochemical positivity for mithochondrial antigen [3], keratin, alpha-1-antichymotrypsin [4]. On ultrastructural analysis numerous mitochondria seemed to fill the cytoplasm. These organuli were not clear because of fixation of tissue for light microscopy, which is similar to the case reported by Mizutary et al [5]. Other neoplasms that arise from the salivary gland with a granular cytoplasm are oncocytoma, acinic cell adenocarcinoma and salivary duct carcinoma [6].

Oncocytic carcinoma can be differentiated from benign oncocytoma by the presence of a connective tissue capsule in the latter. Moreover, compared to oncocytoma, oncocytic carcinoma usually shows a greater mitotic activity and more nuclear pleomorphism.

Acinic cell adenocarcinoma can be differentiated from oncocytic carcinoma since its cytoplasmic granules are amphophilic or basophilic. Moreover, the patterns of growth in acinic cell adenocarcinoma can be microcystic or papillary and the neoplastic elements are negative for mithochondrial antigen when examined immunohistochemically. Salivary duct carcinoma, in contrast to oncocytic carcinoma, forms duct-like spaces with papillary and cribriform growth and also shows comedonecrosis [6].

The non-neoplastic proliferation of a salivary gland, which can mimic oncocytic carcinoma is oncocytosis. This lesion is a condition that predominantly affects adults over the age of 60 years, and can be differentiated from malignant oncocytoma by the presence of variably sized foci of oncocytic cells within glandular lobules without altering the normal architecture of the gland [6].

Primary oncocytic carcinoma of the salivary glands should also be differentiated from metastatic oncocytic carcinomas to the salivary glands from a precise clinical history, revealing the previous primary neoplasm and by specific immunohistochemical studies.

Metastatic oncocytic carcinoma of the thyroid (Hürthle cell carcinoma) can be diagnosed because of the immunohistochemical expression of thyroglobulin [7]. 
The diagnosis of a rare metastatic oncocytic adenocarcinoma of the stomach to the salivary gland is facilitated by the presence of a tubular pattern of growth and by the presence of microvilli on the luminal surfaces of neoplastic cells, which are absent in salivary oncocytic carcinoma of the salivary gland [8].

Metastatic renal cell carcinoma, the granular type, must be considered in the differential diagnosis of primary oncocytic carcinoma in a salivary gland. This variant of renal carcinoma is characteristically composed of cells organized in sheets, cords or as papillary fronds [9]. On immunohistochemical examination, oncocytic carcinoma in a salivary gland is negative for carcinoembryonal antigen (CEA) and S-100 protein [10] in contrast with renal carcinoma $[11,12]$ which is positive to either markers. In our case, the diagnosis of primary oncocytic carcinoma of parotid gland was made by immunohistochemical analysis revealing negativity for S100 and CEA according to other studies reported in the literature [10] and by a negative clinical history for a renal tumour.

The prognosis of oncocytic carcinoma in salivary gland is not well known, because of its rarity. Goode and Corio have reported that tumours smaller than $2 \mathrm{~cm}$ in diameter appeared to have a better prognosis than those that were larger [13].

In our case, the neoplasm was $2.5 \mathrm{~cm}$ in diameter and was not associated with local or distant metastases. A good prognosis is expected for our patient, because there was not involvement of the lymph nodes.

\section{Conclusion}

Oncocytic oncocytic carcinoma may have similar morphologic features with other neoplasms. However histological, immunohistological and ultrastructural features will aid in differentiating one from the other.

\section{Competing interests}

The author(s) declare that they have no competing interests.

\section{Authors' contributions}

GG: Wrote the manuscript and did the pathological workup

MG: Did the pathological work-up and prepared photomicrographs

LG: reviewed the literature and helped in preparation of manuscript

TF: operated on the patient and revised the manuscript

\section{Acknowledgements}

Written permission was obtained from the patient for publication of this case report. The Authors wish to express their gratitude to Mrs Emilia

Corradini and Mrs Gabriella Becchi for technical assistance.

\section{References}

I. Guclu E, Oghan F, Ozturk O, Alper M, Egeli E: A rare malignancy of the parotid gland: oncocytic carcinoma. Eur Arch Otorhinolaryngol 2005, 262:567-569.

2. Ellis GL, Auclair PL, Gnepp DR, Goode RK: Other malignant epithelial neoplasms. In Surgical pathology of the salivary glands Saunders W Philadelphia; | 991:455-488.

3. Shintaku M, Honda T: Identification of oncocytic lesions of salivary glands by anti-mitochondrial immunohistochemistry. Histopathology 1997, 31:408-4II.

4. Muramatsu T, Hashimoto S, Lee MW, Chung CK, Matsuzaki K, Inoue $\mathrm{T}$, Noma $\mathrm{H}$, Shimono M: Oncocytic carcinoma arising in submandibular gland with immunohistochemical observations and review of the literature. Oral Oncol 2003, 39:199-203.

5. Mazutari K, Naganishi h, Tanaka Y: Oncocytic carcinoma in the submandibular gland of a case based on anti-mitochondrial immunohistochemical observation. Auris Nasus Larynx 2005, 32:305-308.

6. Ellis GL, Auclair PL: Oncocytic carcinoma. In Atlas Tumour Pathology. Tumour of salivary glands 3rd series, fascicle 17 Armed Forces Institute of Pathology. Washington DC; 1996:318-324.

7. Johnson TL, Lloyd RV, Burney ER, Thompson NW: Hürthle cell thyroid tumours. An immunohistochemical study. Cancer 1987, 59:107-12.

8. Takubo K, Honma N, Sawabe M, Arai T, Izumiyama-Shimomura N, Kammori M, Sasajima K, Esaki Y: Oncocytic adenocarcinoma of the stomach. Am J Surg Pathol 2002, 26:458-465.

9. Murphy WL, Bruce Beckwith J, Farrow GM: Tumours of the kidney. In Atlas Tumour Pathology. Tumour of the kidney, bladder, and related urinary structures 3rd series, fascicle II Armed Forces Institute of Pathology, Washington DC; 1994: I I0-1 I 2.

10. Alberty J, August C, Stoll W: Oncocytic neoplasms of the parotid gland. Differential diagnosis, clinical course and review of the literature. HNO 200I, 49:109-17.

II. Ghazizadeh M, Kagawa S, Kurokawa K: Immunohistochemical studies of human renal cell carcinomas for $A B O(H)$ blood group antigens, $T$ antigen-like substance and carcinoembryonic antigen. JUrol 1985, 133:762-766.

12. Takashi M, Haimoto H, Murase T, Mitsuya H, Kato K: An immunochemical and immunohistochemical study of $\mathrm{S} 100$ protein in renal cell carcinoma. Cancer 1988, 61:889-895.

13. Goode RK, Corio RL: Oncocytic adenocarcinoma of salivary glands. Oral Surg Oral Med Oral Pathol 1988, 65:61-66.
Publish with Bio Med Central and every scientist can read your work free of charge

"BioMed Central will be the most significant development for disseminating the results of biomedical research in our lifetime. "

Sir Paul Nurse, Cancer Research UK

Your research papers will be:

- available free of charge to the entire biomedical community

- peer reviewed and published immediately upon acceptance

- cited in PubMed and archived on PubMed Central

- yours - you keep the copyright

Submit your manuscript here:

http://www.biomedcentral.com/info/publishing_adv.asp
BioMedcentral 